\title{
A personal view of the role of the chaplain at the Reaside Clinic
}

\author{
Joseph Stephens
}

The contribution of the chaplain to patient care is rarely discussed and is sometimes forgotten. This paper discusses the role of the chaplain in a regional secure unit.

The Reaside Clinic is the largest regional secure unit in the UK and it is the in-patient facility of the West Midlands forensic psychiatry service. This paper is a description of how one person who is a white, male, Anglo-Saxon, senior citizen from a particular branch of the Christian tradition, namely Methodist but with a lot of ecumenical experience, perceives the role of chaplain in the clinic.

In 1948, when the National Health Service was being set up, the Ministry of Health Circular RHB(48)76 stated that "the Management Committee or Board of Governors should appoint a chaplain-or chaplains from more than one denomination - for every hospital for which they are responsible, and these appointments should always be made in consultation with the appropriate Church authorities". In 1977 the DHSS, in correspondence, stated that "under the provisions of $H M(63) 80$ chaplains are appointed to serve both patients and staff in hospitals".

I took on the role of chaplain at the Reaside Clinic when I retired from the full-time pastoral ministry within the Methodist Church at the age of 65. I had been invited to apply for the post of part-time chaplain, and after interview I was appointed, and began work in September 1990. The appointment was for one session a week, although open to me that it be increased to two if necessary. I wished only to be committed to one session but to come in at other times if necessary and always to be on call.

I have always seen myself as chaplain to the whole institution, available to staff and patients alike. But pastorally the priority has always been the patients and support of the staff in their work with the patients, by providing contacts or information.

In one sense every member of staff is part of a chaplaincy team, since many patients have frequent contact with those whose work is cleaning, catering, maintenance or administration, as well as with people with specialist skills or belonging to professional disciplines. All are involved in some way in caring and healing. A paper seeking to define standards of chaplaincy work in the NHS distinguishes between spiritual, religious and cultural aspects of care (Woodward, 1990). It defines spiritual as: "The essentially human, personal and interpersonal dimension, which integrates and transcends the cultural, religious, psychological, social, and emotional aspects of the person". So using that definition of 'spiritual', many, if not all staff, are exercising spiritual care as part of their professional role. Equally all are seeking to give culturally appropriate care, "based on the principles of justice and equity. It assumes a sensitivity to, and awareness of, the attitudes, traditions and customs of people who belong to different communities within society."

The chaplain is especially concerned with religious care for those who express their spirituality through religious faith or practice, or both. I have always seen it as my role if appropriate, to bring in the priest or other authorised religious person recognised by the faith community to which the patient belongs. Religious affiliation has both positive and negative effects. To be a practising Roman Catholic or Anglican or Methodist, or a member of the Jesus Army, or a Muslim or Sikh, means you have ideas which may help you to be a whole person, or which mental illness may distort, or carried to extremes may make you fanatical. In a place like Reaside we are constantly reminded of the negative effects.

In the UK, society is secular and multicultural, with a wide diversity of attitudes to religion from atheism to the extreme fundamentalism found not only in Christianity and Islam but in all world faith traditions. The UK is a multi-faith society and one in which there is pluralism within each faith. We are aware, within Christianity, of the Orthodox, Catholic and Protestant traditions and of many variations of each. But the same is true in Islam, Judaism, Hinduism, Buddhism and Sikhism. At Reaside we are made aware of the extreme sects, which are seen by mainstream denominations as heretical but when viewed through Hindu, 
Buddhist or Muslim eyes are seen as part of the Christian tradition.

It is against this background that the concept of chaplaincy must be seen, with the added dimension at Reaside of caring for and treating people suffering from mental illness.

It was clear from the start that the work of the chaplain here would expand. The limiting factors were money and the chaplain's avallability. My appointment was the one session "to be worked flexibly"; I chose to have a regular morning as a routine from which I might deviate, and to be on call at other times.

The chaplaincy to the staff I have used in several ways. If anyone wished I have been a supportive friend who was outside the system. and for myself I have been glad of the friendship and support given. I have benefited from the weekly clinical presentations and the discussions which follow about treatment and management.

The chaplain is also valuable as a resource person; if $I$ do not have the information requested I know where it can be obtained. Examples are where background material on Hindu and Buddhist spirituality was needed, or when literature and a video on the 'Jesus Army' proved invaluable. I have been able to bring in outside help, such as people from the Black and White Christian Partnership with a knowledge of, and expertise in, African spirituality and practices. This has helped where the boundary between ideas resulting from mental illness and those which are part of normal outlook within an unfamiliar religious culture become intermingled.

I have attempted to be available to staff without getting in their way. A similar approach has governed my weekly wanderings through the clinic among the patients. Whether in the units, in the Occupational Therapy Department, in the dining hall or in the corridors, I felt it important for people to be able to avoid me without embarrassment if they wished. I have attempted by this means to lay the foundations for a future relationship with individual patients, should they wish it, which is healing and transforming in the sense that this is the true aim of all that happens in the clinic.

I visit each of the residential units three or four times in the course of the morning, taking every opportunity to relate to individuals or groups. Fortunately I have an endless capacity for drinking cups of tea. The tea-break in the canteen, keep-fit class and other occupational activities provide a chance to be identified with the patients. It often means just being there in front of the TV screen, but opportunities for conversation do come.

At the beginning I decided that the low profile approach, which comes most naturally to me, would be the best one. Except for the carol service I have not worn a clerical collar; and I have encouraged patients to call me "Joe", although I accept happily any designation they wish to give me.

The patients perceive the chaplain in various ways, depending often on their past experience of ministers or of the Church. They may come to accept me as myself, but often begin by seeing me as representing 'the Church' or 'religion'. The immediate reaction may be aggression, manipulation, exaggerated approval or apathy and indifference. This, of course, can be true of the same patients at different stages and their reactions may be distorted by mental illness. But as treatment takes place most patients have come to accept me, and some to trust me.

If patients request it, and the staff agree, I bring in the appropriate person, such as the Roman Catholic priest, someone from the mosque or gurdwara, or their own Christian minister. But I have always protected patients from religious people or institutions if it was clear they wished to have the 'space' to consider alternatives.

Like other members of staff I have not always felt it right to respond to requests that patients make. In particular, I have resisted requests for religious services and have been increasingly hesitant to provide Bibles and other holy books. I have felt that if they wished to attend church they should go to a local community, if they have parole, or to the service on the hospital campus.

The number of requests for Bibles led to a change in my attitude, because I found that the possession of one often led to an unhealthy concentration on passages which fed an imagination already influenced by their mental illness. But in other ways I have been able to respond positively to requests, for personal prayer, confession, and blessing, and for religious objects such as a crucifix, a rosary or a picture. A baptism and a confirmation have been arranged, but not within Reaside.

In individual cases, and especially when recovery was taking place, the Bible and the Koran, and devotional books such as Bible Reading Notes or books of prayers have proved invaluable in helping patients form a pattern of devotion for themselves; their sense of being forgiven and valued has been reinforced; and their concept of the relationship between faith and life has been broadened.

Underlying my approach to chaplaincy is my own religious stance. While recognising that many world faiths, especially Christianity and Islam, are missionary by their nature I accept religious pluralism as positive, the result of God's self-disclosure perceived variously and imperfectly in different cultures. The situation is a dynamic one, and each faith is capable of new insights. 
I believe it is theologically unsound for any religious group, whether Christian, Muslim or Buddhist, to say: "we have the only true way" or "the best way" or "the final truth". They are different from each other, sometimes irreconcilable, but we need to accept one another's faith as a valid expression of religious aspiration and that each tradition has produced its saints.

Religion at its best liberates people, gives them a wider vision, inspires a concern for justice, moderates the extreme attitudes, and gives the moral strength to live unselfishly, working for change in a concerned but non-violent way. But for many patients this has not been their experience of religion or of religious institutions or even of people in positions of religious authority. Some have been enslaved rather than liberated, others have become guilt-ridden instead of experiencing a sense of being forgiven and loved and others have felt excluded rather than accepted.

For these reasons I have carried out my task of chaplain in a low-key manner. If I am to be of help to a patient he or she must first accept my presence and eventually be able to trust me enough to talk freely. What the chaplain has to offer is his or her self (warts and all). My own religious faith is a deep but questioning trust in a God who is both impersonal and personal. Because I was born into the UK, I have drawn my picture of God from the life and teaching of Jesus. I believe we also gain insights into the nature of God through his death on the Cross, and through the experience of the early Christians that there was still a living presence of God with whom they could relate. With the help of God I am what I am; imperfect in many ways, but at peace with myself and concerned about justice in the world and loving, forgiving relationships between people. I believe that all true religion can produce this inner peace anc outgoing love.

\section{Acknowledgements}

I am grateful to all the staff of the Reaside Clinic without whose support, trust and advice my role as chaplain would have been much less effective. and to the many patients who offered thei friendly support. In particular, I thank Professor Robert Bluglass, who has encouraged me by his willingness to read the article and made valuable comments.

\section{Reference}

WOODWARD. J. (1990) South Birmingham Health Authority document. Authortty/Unit Draft Specification for Chaplaincy Services.

Joseph Stephens, Chaplain to the Reaside Clinic, Bristol Road South, Rubery, Rednal, Birmingham B45 9BE 